\title{
Storm evolution characterization for analysing stone armour damage progression
}

\author{
Melva Martín-Hidalgo , Mª Jesús Martín-Soldevilla , Vicente Negro , \\ Paloma Aberturas , J.S. López-Gutiérrez
}

A R T I C L E I N F O

Keywords:

Storm evolution

Multivariate statistics

Armour damage

Damage progression

\begin{abstract}
A B S T R A C T
Storm evolution is fundamental for analysing the damage progression of the different failure modes and establishing suitable protocols for maintaining and optimally sizing structures. However, this aspect has hardly been studied and practically the whole of the studies dealing with the subject adopt the Equivalent triangle storm. As against this approach, two new ones are proposed. The first is the Equivalent Triangle Magnitude Storm model (ETMS), whose base, the triangular storm duration, $D$, is established such that its magnitude (area describing the storm history above the reference threshold level which sets the storm condition), $H_{T}$, equals the real storm magnitude. The other is the Equivalent Triangle Number of Waves Storm (ETNWS), where the base is referred in terms of the real storm's number of waves, $N_{z}$. Three approaches are used for estimating the mean period, $T_{m}$, associated to each of the sea states defining the storm evolution, which is necessary to determine the full energy flux withstood by the structure in the course of the extreme event. Two are based on the Jonswap spectrum representativity and the other uses the bivariate Gumbel copula $\left(H_{s}, T_{m}\right)$, resulting from adjusting the storm peaks. The representativity of the approaches proposed and those defined in specialised literature are analysed by comparing the main armour layer's progressive loss of hydraulic stability caused by real storms and that relating to theoretical ones. An empirical maximum energy flux model is used for this purpose. The agreement between the empirical and theoretical results demonstrates that the representativity of the different approaches depends on the storm characteristics and point towards a need to investigate other geometrical shapes to characterise the storm evolution associated with sea states heavily influenced by swell wave components.
\end{abstract}

\section{Introduction}

Extreme actions in maritime engineering are determined by statistically processing climate variables which allow the design storm's return period for establishing the structure's lifetime to be defined. Statistical characterization of representative environmental variables was traditionally a marginal operation and the significant wave height, $H_{s}$, was considered to be a main variable whilst other variables such as the mean period, $T_{m}$, and the storm direction and duration, $D$, were also somewhat subjectively taken into consideration. Using this approach, the dependency between these variables was not taken into account and, consequently, the risk assumed in structure design remained unknown. An accurate statistical description would require the joint use of all marginal laws in order to obtain a representative multivariate distribution. Several works addressing classical design problems in coastal engineering demonstrate how useful copula functions are in coping with such a problem. The works of Coles and Tawn (1994); Coles et al. (1999); Guedes Soares and Scotto (2001) may be highlighted amongst the first maritime engineering works dealing with the joint behaviour of the representative variables $H_{s}-T_{m}$ by using copula functions. Other studies analyse the joint behaviour of the significant wave height, $H_{s}$, with other variables, such as the works of Morton and Bowers (1996); Nerzic and Prevosto (2000); Zachary et al. (1998) which assume the logistic dependency model for studying the joint behaviour of $H_{s}$ and the wind speed, as well as the joint characterization of $H_{S}-D$ as analysed by Sobey and Orloff (1999). The correlation between storm surge and tides is studied by Tsimplis and Blackman (1997). Combined models of copula functions and functional relations between the variables $H_{s}, T_{m}$ and sea level referring to the wave steepness are used by Hawkes et al. (2002); HR Wallingford and Lancaster University (2000) to establish the joint behaviour of successive storms. These works were hailed as a great advance in multivariate statistical characterisation. However, studies on the multivariate behaviour of the extreme event do not analyse a fundamental aspect, such as the 
characterization of the storm history enabling progressive failure modes to be studied. This research focuses on this aspect in proposing two new approaches and applying them to assess the damage progression on the breakwater armour layer.

There are a great number of multivariate flood storm models that analyse flood and drought evolution in terms of their duration, magnitude or peak value, e.g. (Biondi et al., 2002; De Michele and Salvadori, 2003; Goel et al., 1998; Shiau and Shen, 2001; Yue et al., 1999). Other important advance in hydrological field is the synthetic storm surge hydrograph equation proposed by Cialone et al. (1993), later modified by Zevenbergen et al. (2004) to better represent the falling limb. That equation is used by Melby et al. (2011) in order to model time series of wave and water level parameters.

Unfortunately, only a few approaches can be found in literature to cope with the storm history characterization, among them, the Equivalent Triangle Storm model (ETS), drawn up by Boccotti (2000) adopting a triangular shape, stands out amongst the early work analysing the storm evolution. In this model, the height of the triangle, " $a$ ", is assumed to be equal to the significant wave height at the storm peak. The base of the triangle, " $b$ ", (i.e., the duration of the equivalent triangle storm) is such that the maximum expected wave height of the triangle storm is equal to the maximum expected wave height of the real storm. Having defined the " $a$ " and " $b$ " parameters, the equivalent sea is defined as that part of the theoretical storm above the reference threshold, which sets the storm condition, $H_{T}$. Based on this model, De Michele et al. (2007) introduced the concept of storm magnitude inspired on the hydrological variable to define the flood volume (De Michele and Salvadori, 2003). An extension to the ETS model is that carried out by Arena and Fedele (2002), in order to take the seasonal nature and direction of the storm into account. This study compares the return periods resulting from using the triangle equivalent sea and the total sample methods. Later, Fedele and Arena (2009) presented a generalisation of the ETS model called Equivalent Power Storm (EPS), where a shape parameter, $\lambda$, was introduced, enabling the initial triangular model shape to be varied. Another approach is that of Corbella and Stretch (2012a) who also assumed a triangular shape, but the base is the real storm duration above the reference threshold, $H_{T}$. Most existing models address the evolution of the storm history with a triangular shape. However, this is not the most suitable for reproducing more developed waves (ROM 1.0-09 "Recommendations for the Project Design and Construction of Breakwaters", 2009).

Furthermore, all these approaches concentrate on estimating the design storm's return period but do not explicitly address the estimation of the mean period of each sea state that makes up the storm and this is decisive for determining the structure's vulnerability. Three approaches have been adopted to define the mean period, $T_{m}$.

The study carried out by Thompson and Shuttler (1975) may be highlighted amongst the first dealing with the rubble mound breakwater damage progression, they concluded that the erosion rate is strongly dependent upon the significant wave height, $H_{s}$, decreasing the damage rate with time. They performed a series of trials which Van der Meer (1988); Van der Meer and Pilarczyk (1984) would later analyse, and obtained the ratio between the damage and the number of waves, appropriate for irregular waves. The new wave height parameter, $H_{n}$, proposed by Vidal et al. (1995) for intermediate or shallow water breakwaters design, was the average of the " $n=100$ " highest waves that reach the breakwater during its lifetime, $H_{n}=H_{100}$. This suggestion is based on the fact that at a given time, the damage will be related to the largest waves supported by the breakwater. Later Vidal et al. (2006), using Thompson and Shuttler's (1975) laboratory data, concluded that $H_{50}$ was the most representative parameter to damage prediction and is independent of the wave height distribution. Using the Vidal et al. 2006 wave height parameter, $H_{50}$, instead of the significant wave height, $H_{s}$, in the recent stability formulae, Etemad-Shahidi and Bali (2012) founded that this modification yields more accurate results. Then, two new design formulae were proposed. Another approach is the Medina $(1996,1997)$ exponential equation, attempting to reproduce the number of waves associated to each of the sea states defining the storm history.

Although all this approaches represent a great advance in the final damage knowledge, the damage progression is not considered being an important aspect in order to establish the appropriate maintenance and reparation structure periods. This aspect is considered in Lepetit and Feuillet's (1979) equation which was subsequently amended by

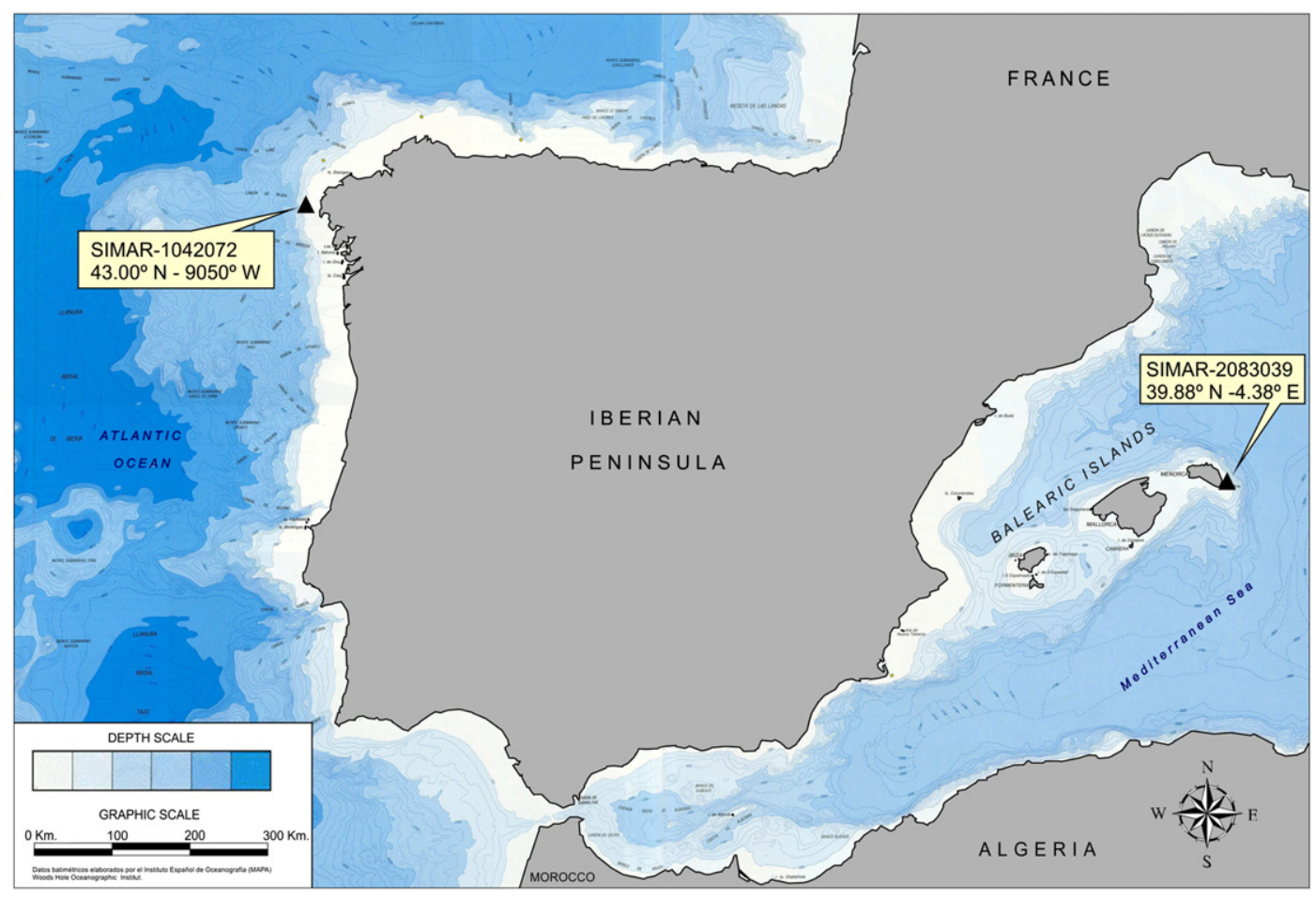




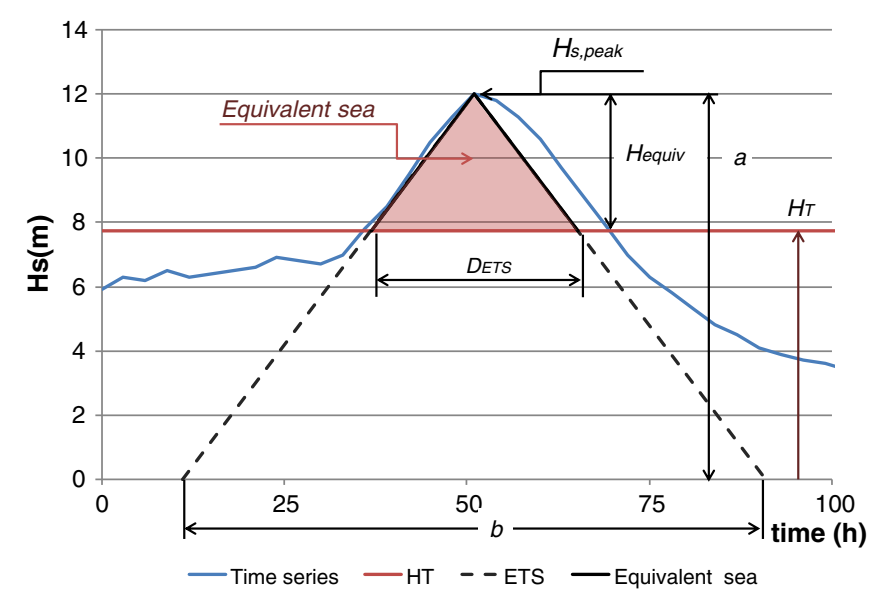

Fig. 2. ETS model parameters and example of modelling.

Teisson (1990) proposing a new power equation to take into consideration the damage as a function of the storm duration and the significant wave height, $H_{s}$

Based on Van der Meer (1988); Van der Meer and Pilarczyk's (1984) formula and with the results of a series of physical model trials, Melby (1999); Melby and Kobayashi (1998) proposed an empirical formula that allows the prediction of mean damage progression with regular wave events, however the formula is limited to new structures because of the zero initial damages assumption. To avoid this shortcoming Melby and Kobayashi (2000a, 2000b) proposed two new methods. In these new methods the damage in every event only depends on the incremental time, thus the predicted damage progression is too sensitive to the wave height change. Using these results and additional tests, Melby and Kobayashi (2011) developed a new model. The model's equations are based on the maximum momentum flux in the incident waves and explicitly include the effect of water depth at the toe of the structure.

This research paper centres on this aspect and proposes two new approaches analysing its accuracy by comparing real and theoretical damage progression on the main armour layer, with the model (Melby and Kobayashi, 2011) used.

\section{Storm characterisation}

In order to assess the possible relationship between storm shapes and the maritime climate characteristics of the study area (i.e., fetch length, wind-wave persistence), two points located in maritime areas of the Spanish coast were selected. One, SIMAR_10442072, located on the NW Peninsular Spanish coast is exposed to developed sea states (swell), whilst the other, SIMAR_2083039, on the NE Mediterranean insular Spanish coast, is exposed to typical sea wave storms. The historical climate data used cover a total of 44 years (from 1958 to 2001) and belong to the hindcast (SIMAR-44) database of Puertos del Estado (State Ports) (Fig. 1).

\subsection{Equivalent Triangular Storm model (ETS), Boccotti (2000)}

The height of the triangle, $a$, in the parametric model proposed by Boccotti (2000), is assumed to be equal to the significant height of the storm peak, $H_{s, p e a k}$, and the base of the triangle, $b$, is the Equivalent Triangular Storm duration, such that the maximum expected wave height of the triangle storm, ETS, is equal to the maximum expected wave height of the real storm, $H_{\max }$, (see Fig. 2). The maximum height is calculated by Borgman, 1970 (1973) as:

$H_{\text {max }}=\int_{0}^{\infty} 1-\exp \left\{\int_{0}^{\mathcal{D}_{\text {Real }}} \frac{1}{T_{m}[h(t)]} \ln \left[1-P\left(H: H_{S}=h(t)\right)\right] d t\right\} d H$

where $D_{\text {Real }}$ is the real storm duration, $h(t)$ is the significant wave height of the storm progression, $T_{m}$ is the mean period, and $P\left(H: H_{s}=h(t)\right)$, the probability of the wave height calculated with the expression proposed by Boccotti, 1997 (2000):

$P\left(H: H_{S}=h\right)=\exp \left[-\frac{4 H^{2}}{H_{S}^{2}\left(1+\psi^{*}\right)}\right]$

where $\psi^{*}$ is the narrow bandedness parameter which, for typical wind waves, takes values between $0.65<\psi^{*}<0.75$, and less than 0.60 for superimposed sea states of sea and swell waves, (Boccotti, 2000). Other different values for this parameter are proposed by Barbaro and Foti (2012) who establish a more selective classification distinguishing between typical wind waves, where $\psi^{*}$ varies in the range between 0.68 and 0.74 , superimposed sea and swell sea states, associated to $\psi^{*}$ values between 0.42 and 0.44 , and swell waves with $\psi^{*}$ between 0.18 and 0.23 .

Considering the values of $\psi^{*}$ proposed by Boccotti, taking the approach of (Rice, 1945), in agreement with the author, for calculating

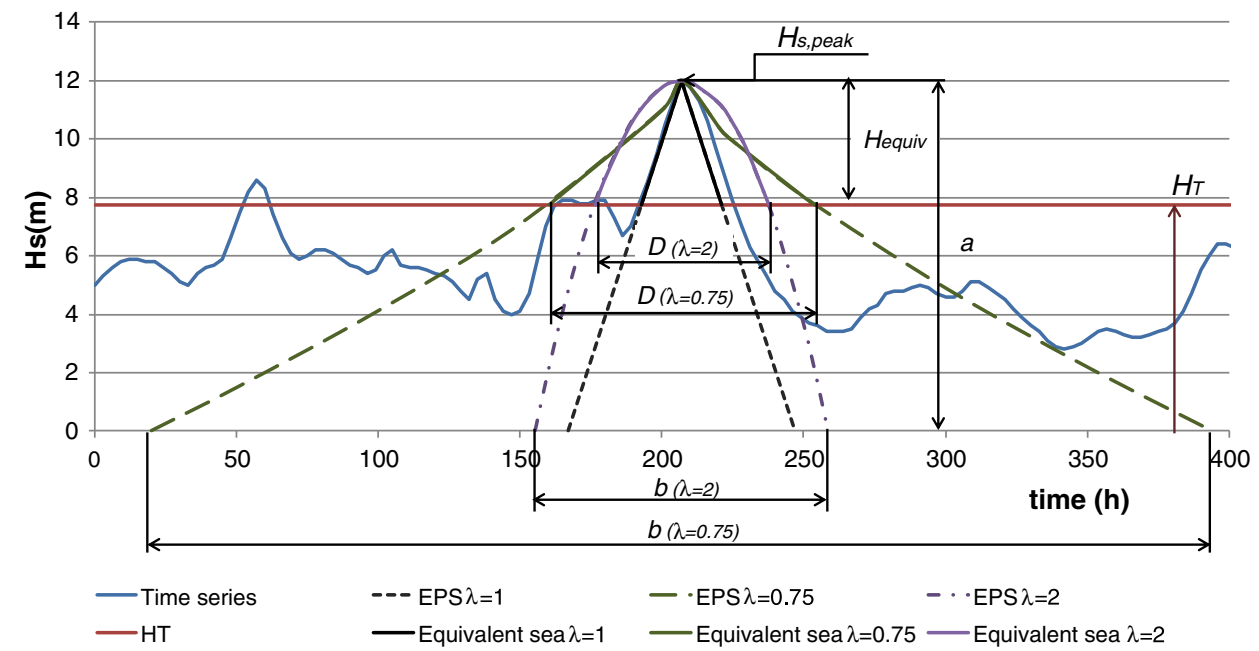




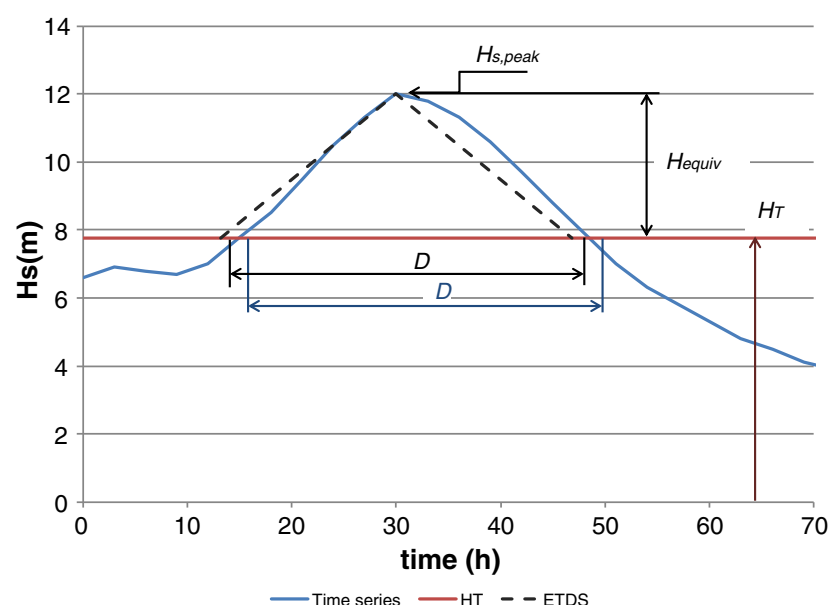

Fig. 4. EDTS model parameters and example of modelling.

$T_{m}:$

$T_{m}=6.6 \pi \sqrt{\frac{\mathrm{H}_{\mathrm{S}}}{4 \mathrm{~g}}}$

and starting from an initial base, $b$, iterations are made until getting ETS model's $H_{\max }$ to equal the corresponding real storm. The maximum height corresponding to the ETS model is:

$H_{\max }=\int_{0}^{\infty} 1-\exp \left\{\frac{b}{a} \int_{0}^{a} \frac{1}{T_{m}[h(t)]} \ln \left[1-P\left(H: H_{S}=h(t)\right)\right] d h\right\} d H$.

Having defined the " $a$ " and " $b$ " parameters, the equivalent sea is defined as that part of the theoretical storm above the reference threshold, which sets the storm condition, $H_{T}$, (see Fig. 2). Therefore, the equivalent sea is defined by the equivalent wave height, $H_{\text {equiv }}=H_{s, \text { pea }} \mathrm{k}-H_{T}$, (the difference between the significant wave height at the storms peak, $H_{s, p e a k}$, and that defining the exceedance threshold which sets the storm's condition $H_{T}$ ), and the base, the theoretical storm duration, $D_{E T S}$, corresponding to the time the geometric shape remains above the reference threshold, $H_{T}$.

\subsection{Equivalent Power Storm model (EPS), Fedele and Arena (2009)}

The Equivalent Power Storm model, proposed by Fedele and Arena (2009), is the generalisation of Bocotti's ETS model, 2000, which includes a shape parameter, $\lambda$, enabling the initial triangular model

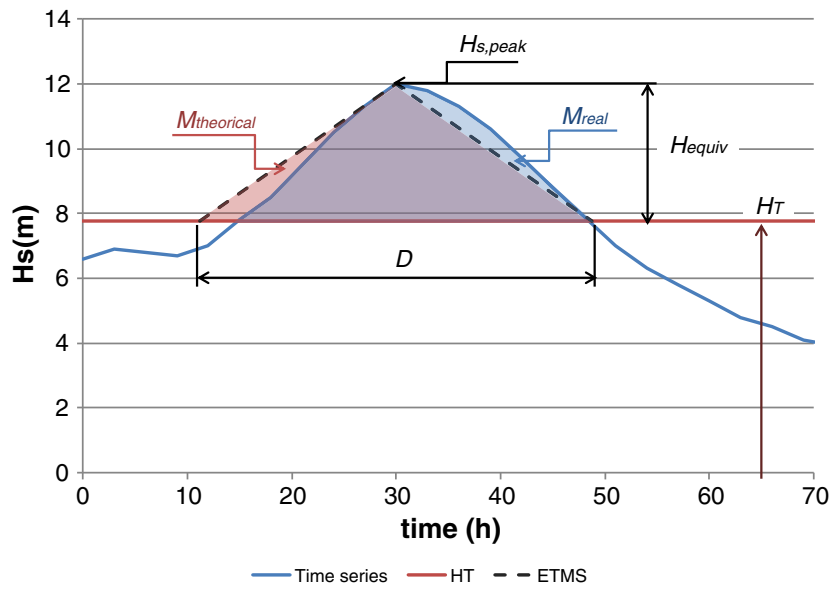

Fig. 5. ETMS model parameters and example of modelling.

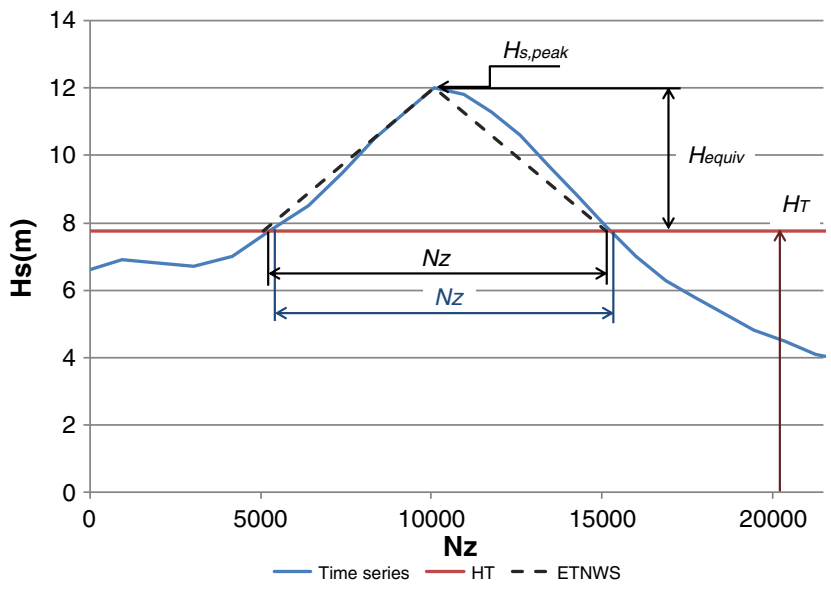

shape to be varied. The $a$ and $b$ parameters are the same as in the ETS model. The parameter $a$ is assumed to be equal to the significant height of the storm peak, $H_{s, p e a k}$ and the base, $b$, is the duration of the geometrical shape defined such that the maximum expected wave height of the triangle storm, EPS, is equal to the maximum expected wave height of the real storm, $H_{\max }$, (see Fig. 3). The maximum height is calculated by Eq. (1), (Borgman, 1970, 1973). The base, $b$, is calculated by making iterations until getting the expected maximum height significant wave, $H_{\max }$, of the theoretical storm to equal the real one. and the latter is defined by:

$H_{\max }=\int_{0}^{\infty} 1-\exp \left\{\frac{b}{\lambda a} \int_{0}^{a} \frac{\ln \left[1-P\left(H: H_{S}=h(t)\right)\right]}{T_{m}[h(t)]}\left(1-\frac{h}{a}\right)^{\frac{1}{\lambda}-1} d h\right\} d H$.

The value of $\lambda=1$ is that corresponding to the ETS model and for $\lambda=2$ the storm is modelled with a parabolic shape.

As in ETS and EPS models the equivalent sea is defined and is characterised as that part of the theoretical storm above the reference threshold, $H_{T}$, (see Fig. 3).

\subsection{Equivalent Triangle Duration Storm (ETDS), Corbella and Stretch (2012a)}

This model consider a triangular shape of equivalent height, $H_{\text {equiv }}$ and base, $D$, the duration associated to the time the real storm remains above $H_{T}$, (Corbella and Stretch, 2012a), this model is used (Corbella and Stretch, 2012b, 2013) later, see Fig. 4.

\subsection{Equivalent Triangle Magnitude Storm, (ETMS)}

A new triangular approach is proposed based on the storm magnitude, $M$, which is a concept introduced by De Michele et al. (2007). In this model, the triangle height is obtained in terms of the equivalent height, $H_{\text {equiv, }}$ and the base, the theoretical storm duration $D_{\text {equiv }}$, is established such that its magnitude (area describing the storm history above $H_{T}$ ), equals the real storm (see Fig. 5).

\subsection{Equivalent Triangle Number of Waves Storm, (ETNWS)}

The other approach proposed considers that the theoretical triangle storm is defined in terms of the equivalent wave height, $H_{\text {equiv, }}$ and the real storm number of waves, $N_{z}$, for defining the triangle base, (see Fig. 6).

The storm peak in all the models is assumed to be the middle of the storm history. 


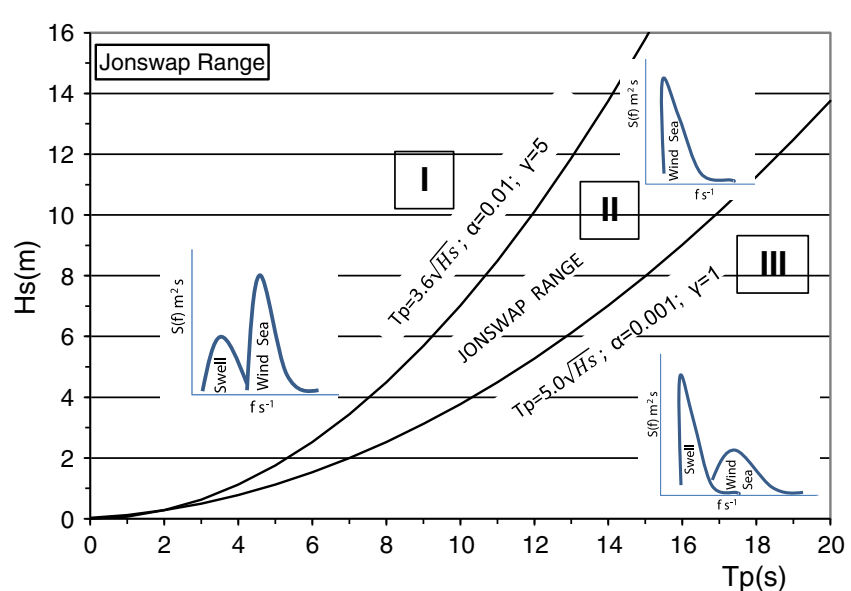

Fig. 7. Jonswap range as function of $H_{s} \& T_{p}$ (Torsethaugen et al., 1984).

\subsection{Evolution of the mean period in the course of a storm}

The studies mentioned do not establish the way for which the mean period, Tm, should be chosen in each storm sea state. This is an important limitation if the damage progression of a maritime structure is to be analysed since both significant height, $H_{s}$, and mean period, $T_{m}$, determine the total energy flux withstood by the structure during its lifetime, (Martín Soldevilla and Aberturas Ajenjo, 2001; Medina, 1996; Vidal et al., 1995). In order to analyse this effect, three different approaches are used, see Fig. 9.

The first approach based on the representativeness of the Jonswap spectrum for storm conditions and uses the expression proposed by Rice (1945).

$T_{m}=6.6 \pi \sqrt{H_{s} / 4 g}$.

The second approach takes into consideration both, the Jonswap spectrum's application limits established by Torsethaugen et al. (1984) for the different types of wave (see Fig. 7), and wave characteristics in the project area. The upper limit (zones I-II of Fig. 7), is representative for the NE Balearic Island coast storms:

$T_{\mathrm{m}} \approx \frac{3.6}{1.2} \sqrt{\mathrm{H}_{\mathrm{s}}}$

and the lower limit for more developed waves (zones II-III of Fig. 7) typical of the NW Peninsular Spanish coast storms.

$T_{\mathrm{m}} \approx \frac{5}{1.2} \sqrt{\mathrm{H}_{\mathrm{s}}}$

In the third approach, proposed by Martín Soldevilla et al. (2009) for designing structures, use was made of the copula functions (multivariate distribution functions whose arguments are the marginal distributions of initial variables). The characteristics of extreme multivariate events are analysed in terms of significant wave height at the storm's peak $H_{s, p e a k}$ and the concomitant mean period, $T_{m, \text { peak, }}$ of each of the storms. Different Archimedean copulas are used by Corbella and
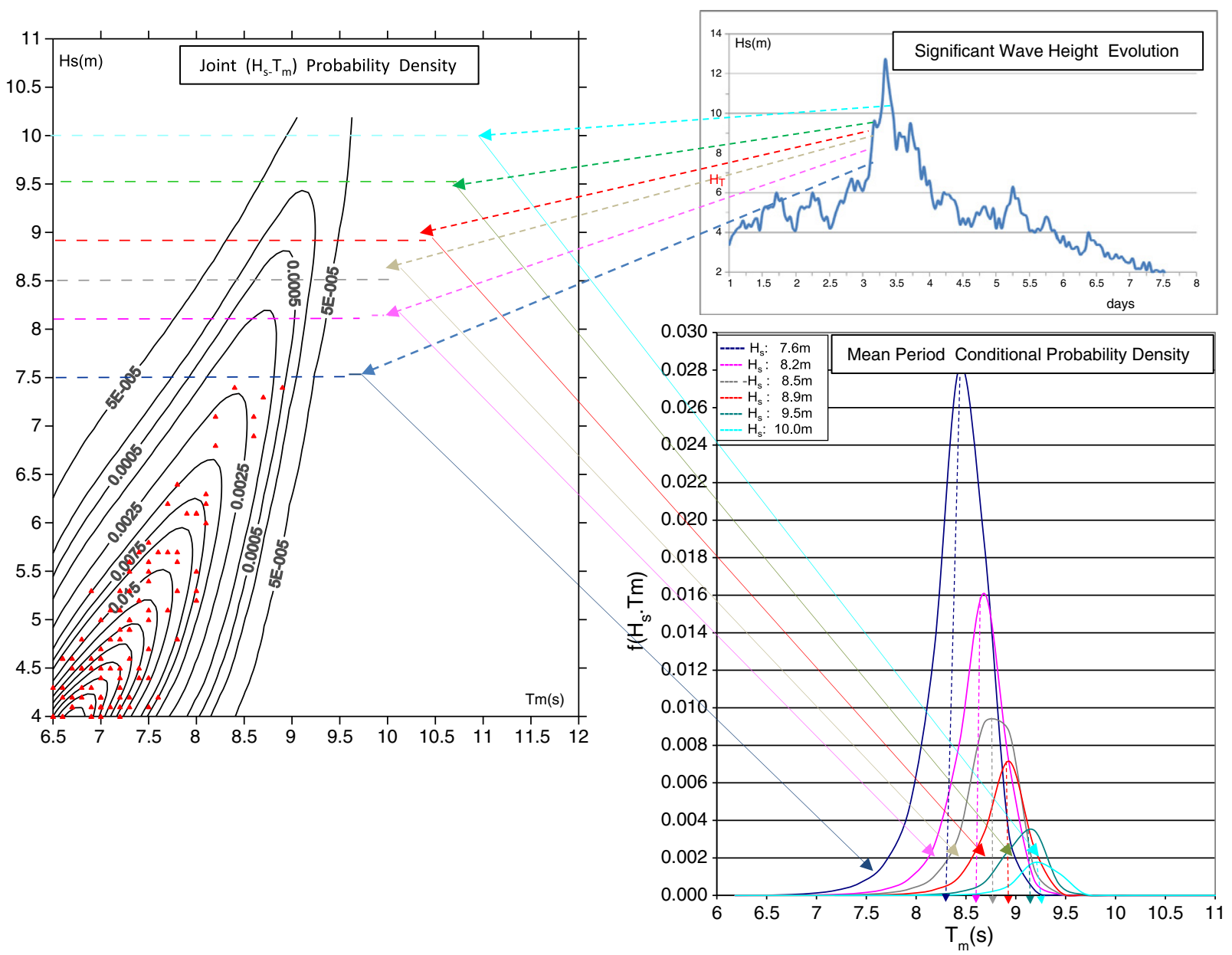


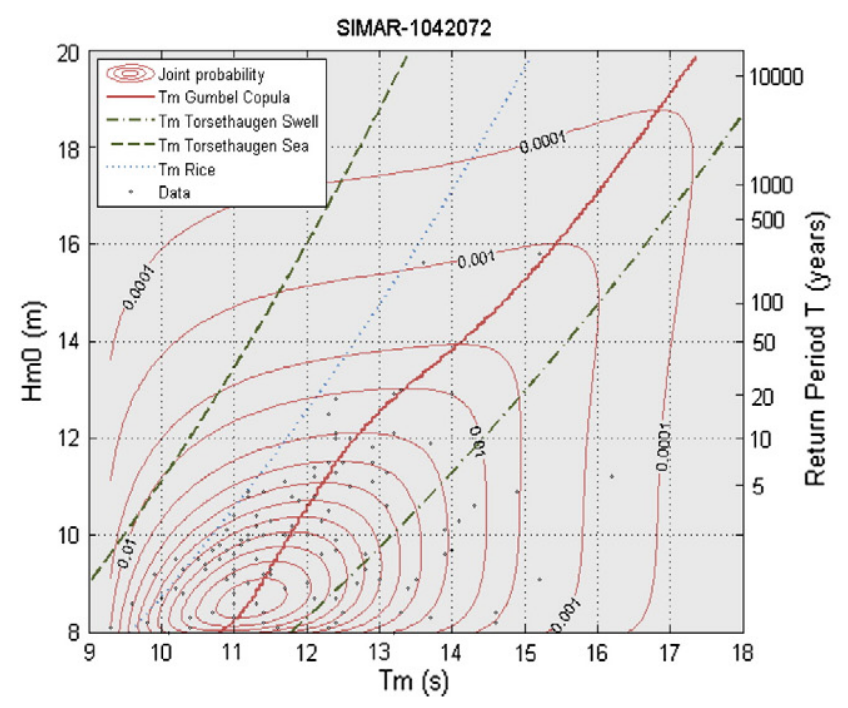

Stretch (2013) to study the correlation between these variables and the conclusion is that they offer good results. The Frank and Gumbel copulas are used which offer good results. The results obtained with the Gumbel copula which belongs to the Archimedean family and also of Extreme Value are presented in this study. Its expression is

$C(u, v, \theta)=\exp \left\{(-\ln u)^{\theta}+(-\ln v)^{\theta}\right\}$ to $\theta \geq 1$

where $u$ is the marginal distribution of the random variable $X=H_{s}$, $u=F(X), v$ is the marginal distribution of the random variable $Y=T_{m}, v=F(Y)$ and $\theta$ is the dependency parameter.

Based on this copula, the authors propose to select the most likely period for each wave height from the theoretical joint density function (Fig. 8).

$f\left(H_{s}, T_{m}, \theta\right)=C(u, v, \theta) \frac{(-\ln u)^{\theta-1}(-\ln v)^{\theta-1}}{\left[(-\ln u)^{\theta}+(-\ln v)^{\theta}\right]^{2-\frac{1}{\theta}}}\left\{\theta-1+\left[(-\ln u)^{\theta}+(-\ln v)^{\theta}\right]^{\frac{1}{\theta}}\right\}(u v)^{-1} f(u) f(v)$.

The mean periods resulting from the different approaches are presented in Fig. 9 together with functions of theoretical density and the initial variables.

\section{Analysing rubble mound breakwater damage progression}

The Melby and Kobayashi (2011) formula is used for checking the representativity of the theoretical storm resulting from the different approaches and the final damage is analysed, as well as its progression

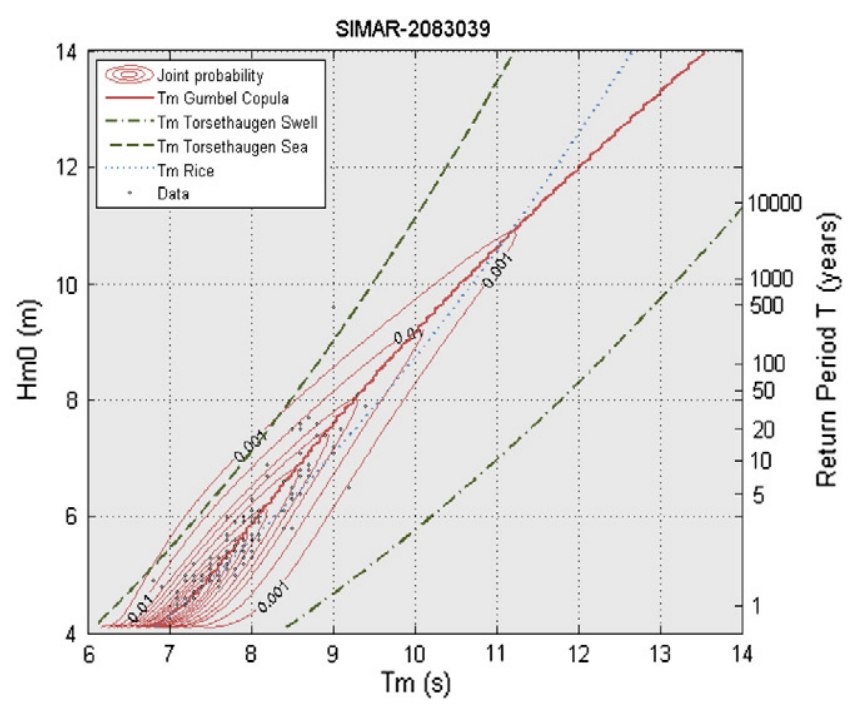

in the course of both the real and the theoretical storms. The empirical formula proposed by the authors uses the concept of the maximum wave momentum flux at the toe of the structure.

Using the linear wave theory, the maximum wave momentum flux is defined as:

$\frac{\left(M_{F}\right)_{\max }}{\gamma_{w} g h^{2}}=\frac{1}{2} \frac{H_{s}}{h} \frac{\tan k h}{k h}+\frac{1}{8}\left(\frac{H_{s}}{h}\right)^{2}\left[1+\frac{2 k h}{\sinh k h}\right]$

where $\gamma_{w}$ is the water density, $g$ the acceleration of gravity and $k=2 \pi / L$ is the number of waves. For non linear waves, the empirical formula of Hughe (2004) is used:

$\frac{\left(M_{F}\right)_{\max }}{\gamma_{w} g h^{2}}=A_{0}\left(\frac{h}{g T_{m}^{2}}\right)^{-A_{1}}$ with $: A_{0}=0.639\left(\frac{H_{s}}{h}\right)^{2.026} \& A_{1}=0.189\left(\frac{H_{s}}{h}\right)^{-0.391}$.

The expression proposed to estimate the damage progression is:

$S\left(t_{n}\right)=K_{s} \sqrt{N_{z e}+\left(N_{z}\right)_{n}}\left(a_{m} N_{m}\right)_{n}^{5}$, with $n=1$ to $n$ sea states

where $K_{s}$ is an added parameter for analysing subsequent damage, $N_{z e}$ the equivalent number corresponding to damage $S_{n-1}$, $N_{z e}=\left(S_{n-1} / K_{s}\left(a_{m} N_{m}\right)_{n}^{5}\right)^{2},\left(N_{z}\right)_{n=j}$ the total number of waves withstood by the structure in the course of the sea state associated to a segment of the storm with a duration $d t_{j}=t_{j}-t_{j-1}$ where

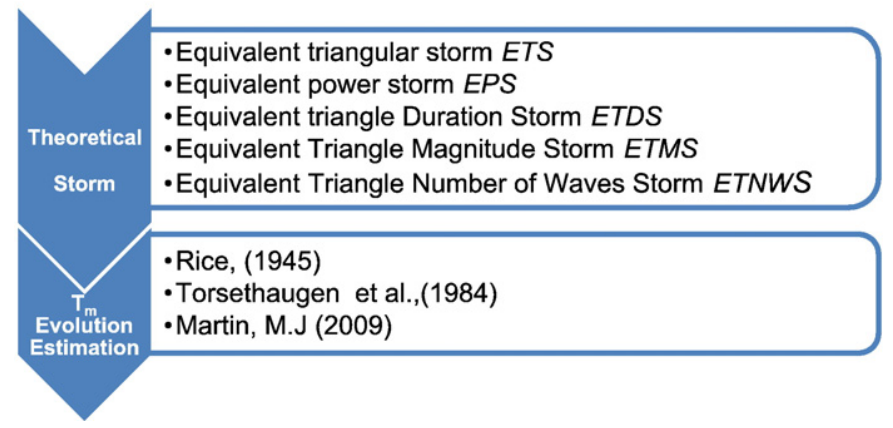

Fig. 10. Scheme of the approaches used. 
$\left(N_{z}\right)_{j}=d t_{j} / T_{m j}$ and $a_{m}$ a parameter depending on the porosity, $P$, the slope $\theta$, and the steepness, $s_{m}$, of each sea state:

$a_{m}=1 /\left(5 \cdot P^{0.18} \sqrt{\cot \theta}\right), \quad$ for breaking in plunging $s_{m} \geq s_{m c} s_{m} \geq s_{m c}$ $a_{m}=s_{m}{ }^{P / 3} /\left(5 \cdot P^{0.18}(\cot \theta)^{0.5-P}\right) \quad$ for breaking in surging $s_{m}<S_{m c}$

with $s_{m c}$ the critical steepness given by $s_{m c}=-0.0035 \cot \theta+0.028$, $N_{m}$ is the stability number depending on the wave momentum flux, is obtained:

$N_{m}=\left(\frac{\left(M_{F}\right)_{\max }}{\gamma_{w} g h^{2}} \frac{K_{\alpha}}{\Delta}\right)^{1 / 2} \frac{h}{D_{n 50}}$

where $\Delta=\left(S_{r}-1\right)$; with $S_{r}=\gamma / \gamma_{w}$ specific gravity of stone, with $\gamma$ the density of the stone, $K_{\alpha}$ is a coefficient in turn containing $K_{m}$ and $K_{r}$, empirical coefficients for taking into account "the relation such as a stone angularity or shape, superface, and stone interlocking".

Fifteen theoretical storms resulting from considering six models (ETS, EPS (for $\lambda=0.75$ and $\lambda=2$ ), ETDS, ETMS, ETNWS), and different approaches for the mean period definition are considered (see Table 2, Fig. 10).

The representativity of the different approaches is analysed by reproducing the history of real storms and the corresponding theoretical ones in the damage progression model proposed by Melby and Kobayashi (2011).

The accuracy of the different approaches is analyzed in terms of the correlation coefficient between the final damage caused by real and theoretical storms (see Table 1 ). The most simplistic method, the observation of the dispersion of real and theoretical damage data (Fig. 11), was also considered as proof of their correctness. a

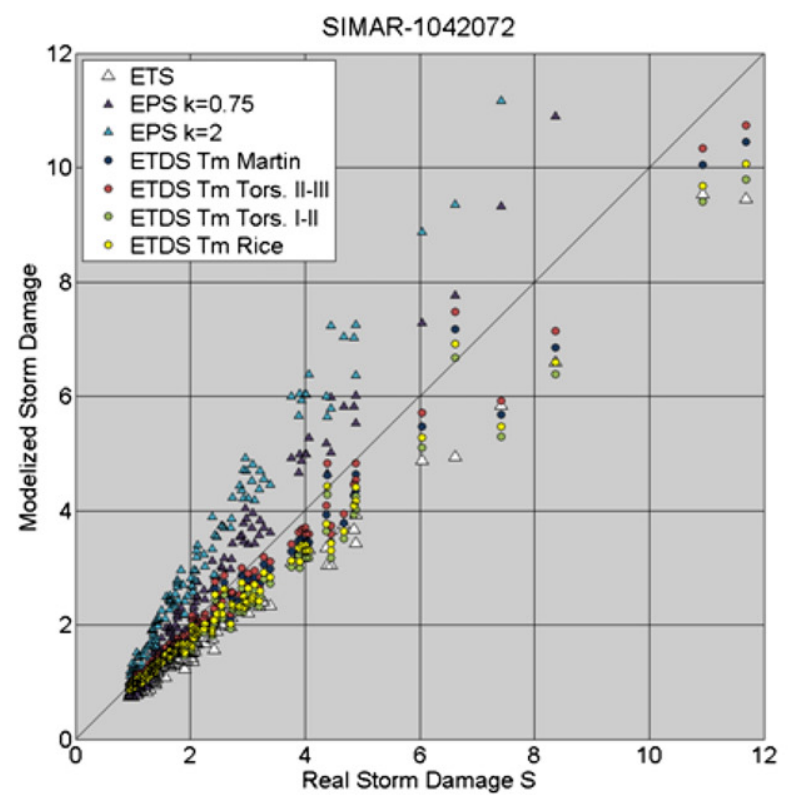

C

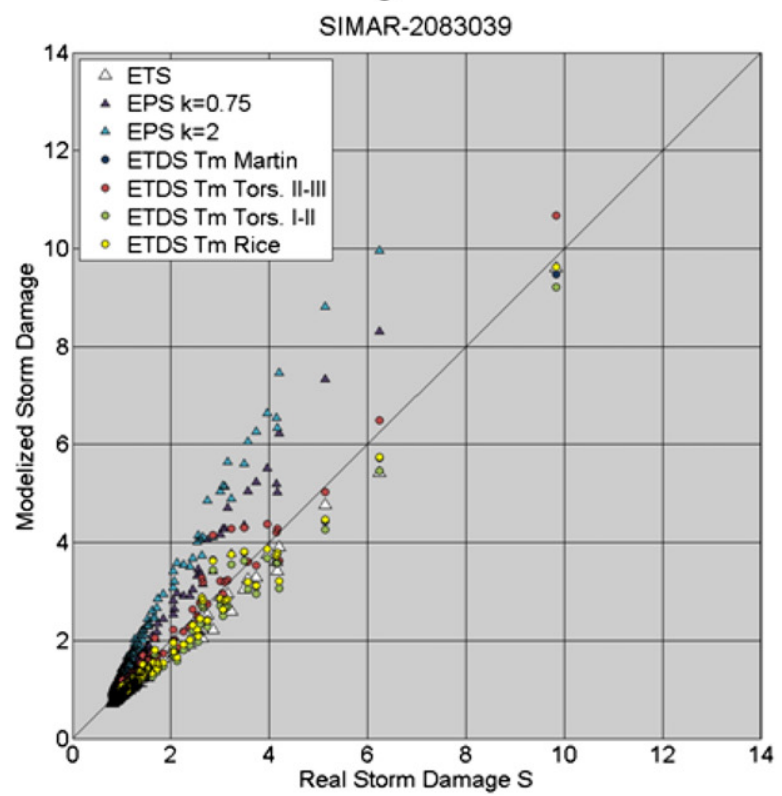

b

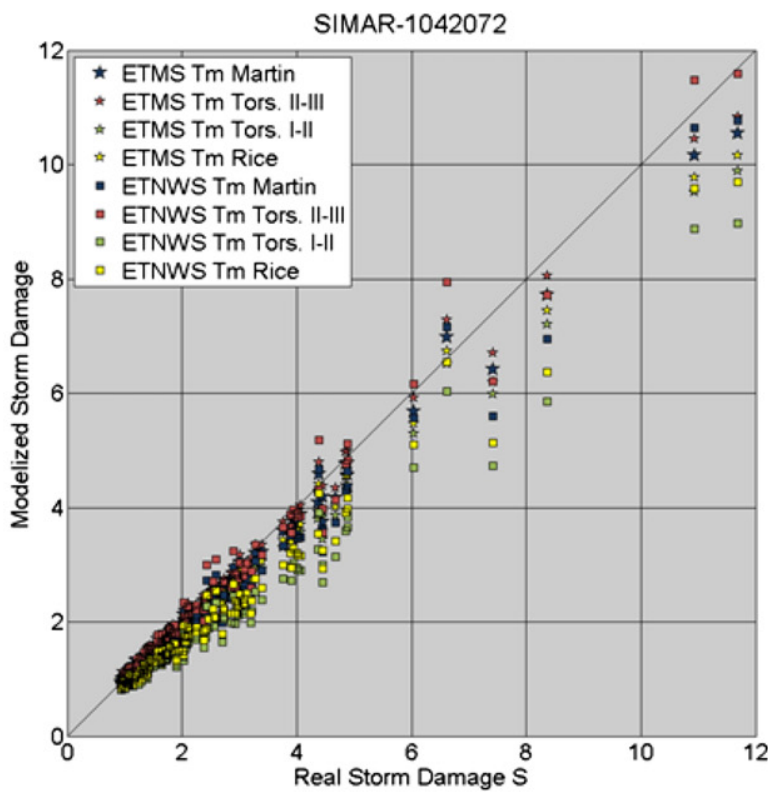

d

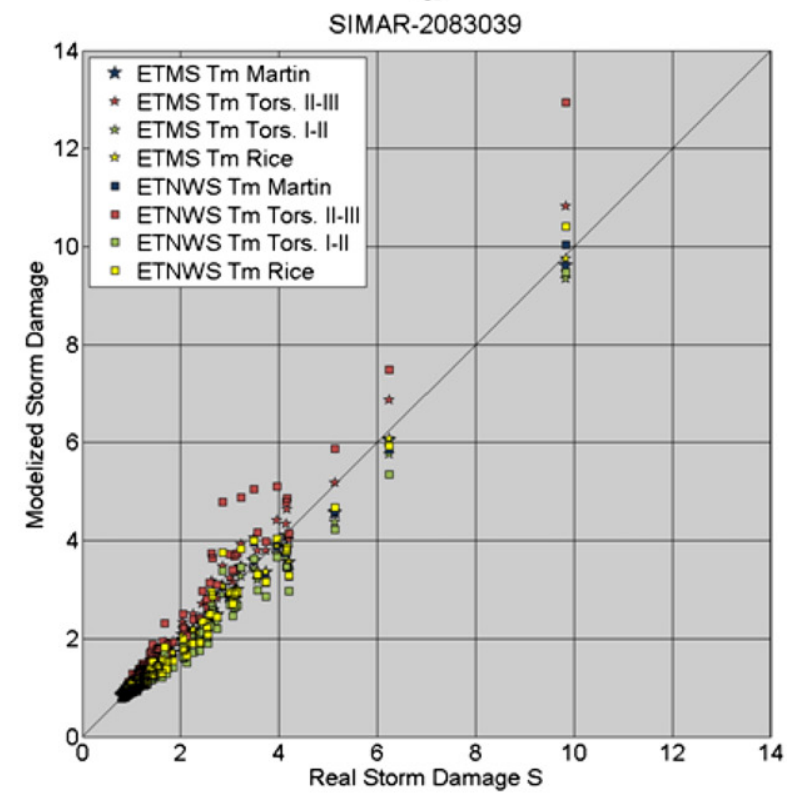


Table 1

Summary of R2 for the different approaches.

\begin{tabular}{llll}
\hline $\begin{array}{l}\text { Theoretical } \\
\text { storm }\end{array}$ & $T_{m}$ approach & SIMAR-1042072 & SIMAR-2083039 \\
\hline ETS & Rice & 0.8681 & 0.9661 \\
EPS $\lambda=0.75$ & Rice & 0.8448 & 0.6778 \\
EPS $\lambda=2$ & Rice & 0.3143 & a) \\
ETDS & Martín & 0.9516 & 0.9687 \\
& Torsethaugen II-III & 0.9684 & 0.9665 \\
& Torsethaugen I-II & 0.9013 & 0.9518 \\
ETMS & Rice & 0.9265 & 0.9697 \\
& Martín & 0.9846 & 0.9907 \\
& Torsethaugen II-III & 0.9911 & 0.9722 \\
ETNWS & Torsethaugen I-II & 0.9506 & 0.9781 \\
& Rice & 0.9691 & 0.9913 \\
& Martín & 0.9512 & 0.9700 \\
& Torsethaugen II-III & 0.9756 & 0.8405 \\
& Torsethaugen I-II & 0.8115 & 0.9404 \\
& Rice & 0.8864 & 0.9693 \\
\hline
\end{tabular}

a) Uncorrelated.

The deviation of damage evolution during the storm is presented for the strongest storms at each SIMAR point studied (Figs. 12 \& 13).

The results obtained show that the ETS model achieves good results for typical sea wave storms although worse than the ETDS approach and the two proposed, ETMS and ETNWS. In the case of storms made up of more developed waves, the ETS model underestimates damage.

In its $\lambda=0.75$ and $\lambda=2$ versions, the EPS model is conservative for all types of storms (typical sea or more developed waves) and theoretical damage between 25 and 60\% higher than the actual are obtained.
Of models existing in the literature, the ETDS is that which best adjusts the damage resulting from typical sea waves storms if the Rice (1945) or Martín Soldevilla et al. (2009) approaches are used to define the mean period. Nevertheless, in the case of more developed waves, this model underestimates damage.

Comparatively, the new ETMS model is more versatile showing the best behaviour with different wave development degrees. The other model proposed, the ETNWS, also performs well. However, it appears to be very sensitive to the choice of the mean period with more developed wave storms. In this case, the approach proposed by Martín Soldevilla et al. (2009), or that referred to by Torsethaugen et al (1984) to define that part of the spectrum associated to the low frequency zone (zones II-III of Fig. 7), offers good results. The approach assuming the Jonwsap spectrum's range of application (Rice, 1945) excessively under assesses.

These results are graphically shown in Figs. 12 and 13 for the most energy containing storm at each SIMAR point studied. The comparison of the real and theoretical damage progression in the storm reflects evolution in the behaviours described for the total data.

The real and theoretical damage progression defined assuming the ETDS, ETMS and ETNWS models is similar for the point located on the NW Spanish coast facing highly developed storms. Nevertheless, slight underassessment is seen in the damage predicted, except in the approach using the ETNWS storm and the $T_{m}$ resulting from the expression referred to by Torsethaugen et al. (1984) for the spectrum's zones II-III.

For the point located on the Mediterranean sea, SIMAR-2083039, the progression of the real and theoretical damage modelled with the ETDS, ETMS and ETNWS and the approach to the mean period proposed by

Table 2

Summary of models for the storm progression approach.

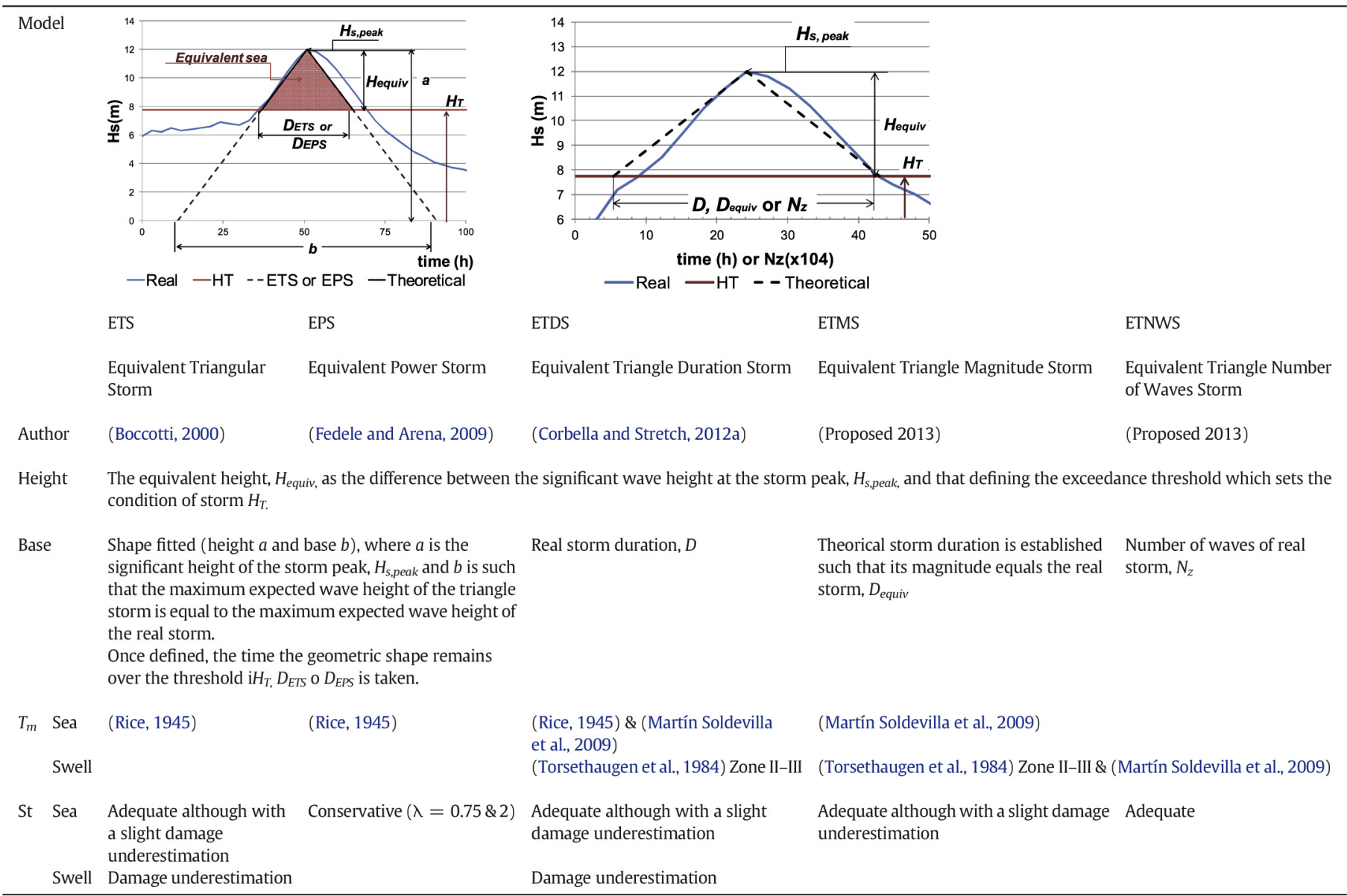


ETS, EPS
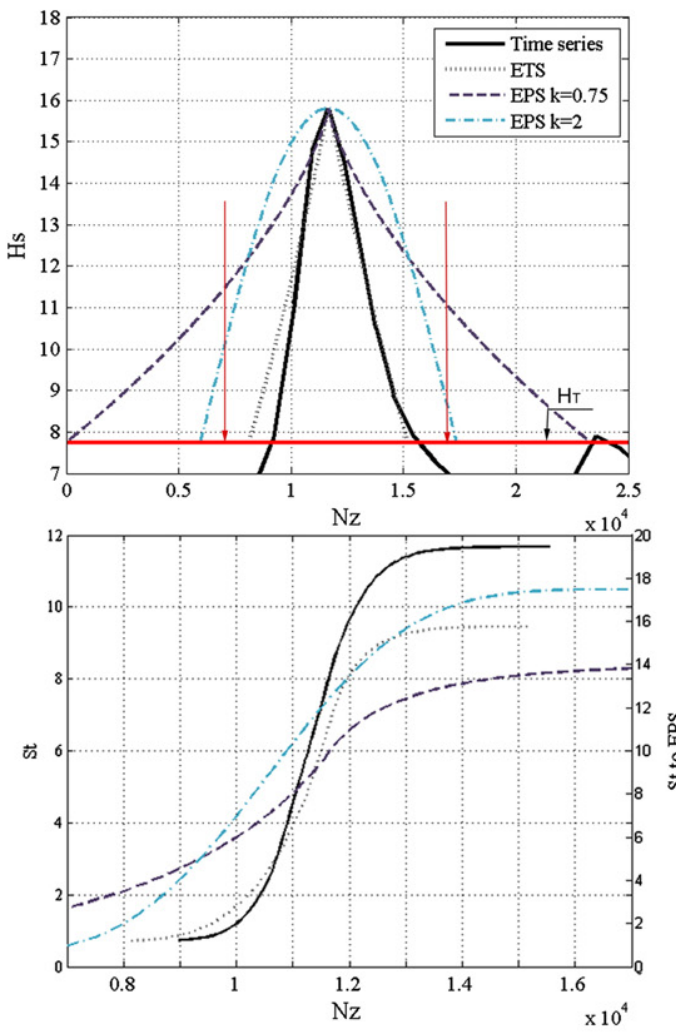

ETMS
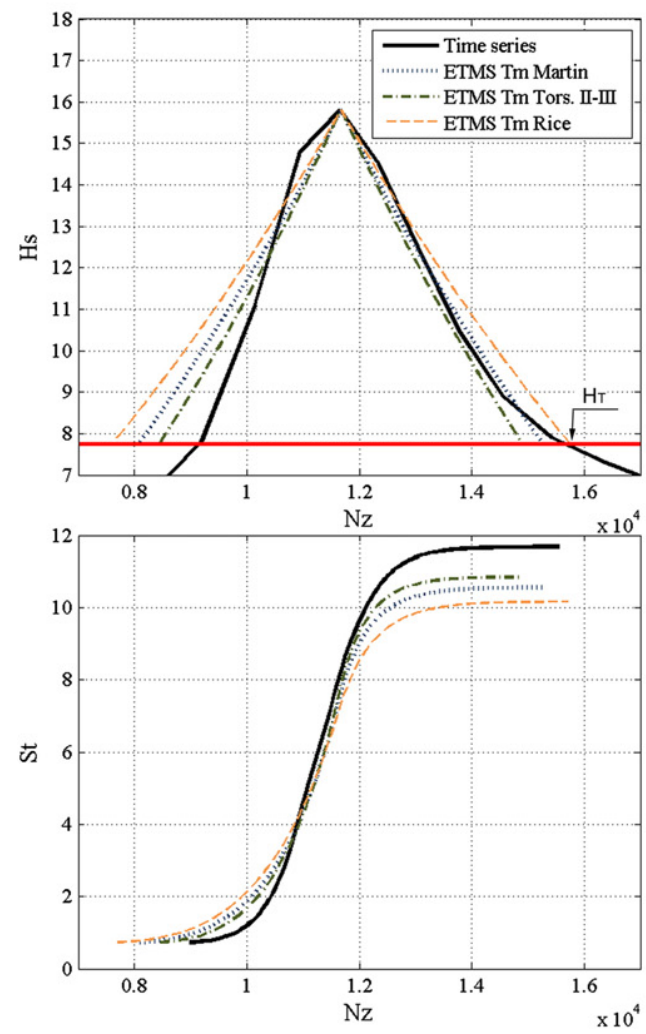

Martín Soldevilla et al. (2009), Rice (1945) or Torsethaugen et al. (1984) to define the high frequency spectrum area (zones I-II Fig. 7), are practically the same. These results are maintained with the rest of the storms analysed.
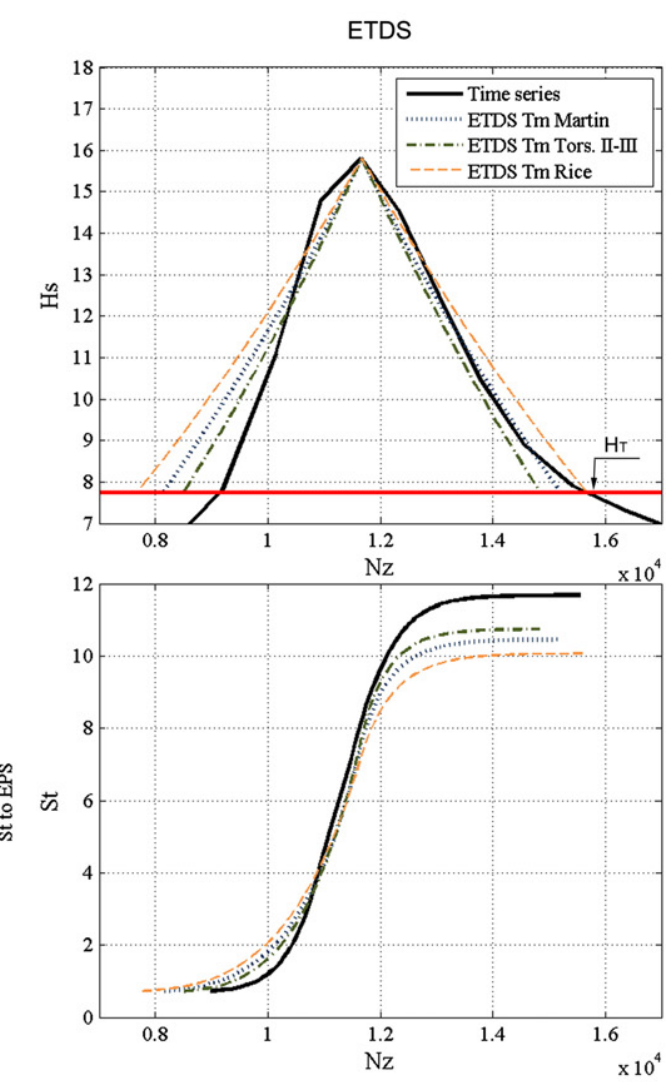

ETNWS
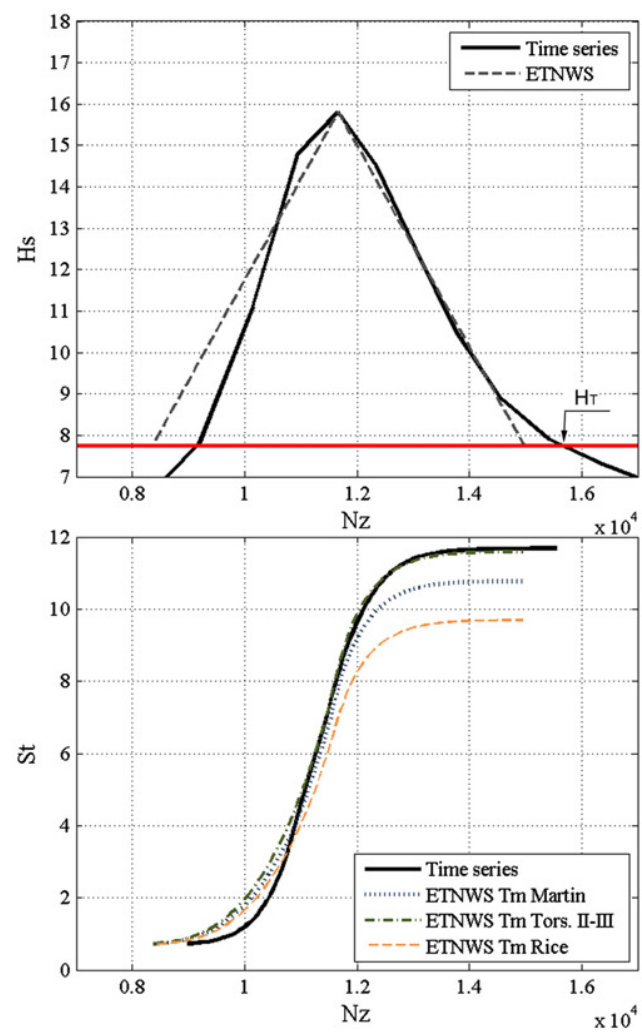

\section{Conclusion}

The ETS model proposed by Boccotti (2000), is acceptable for reproducing the damage progression of maritime structures facing typical sea 
ETS, EPS
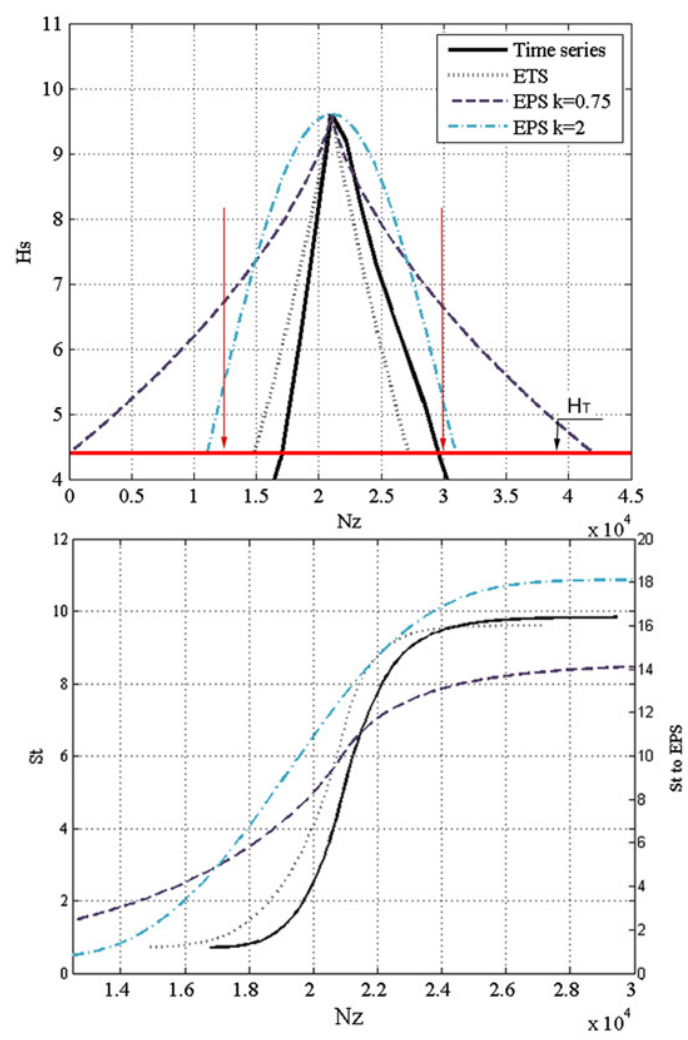

ETMS
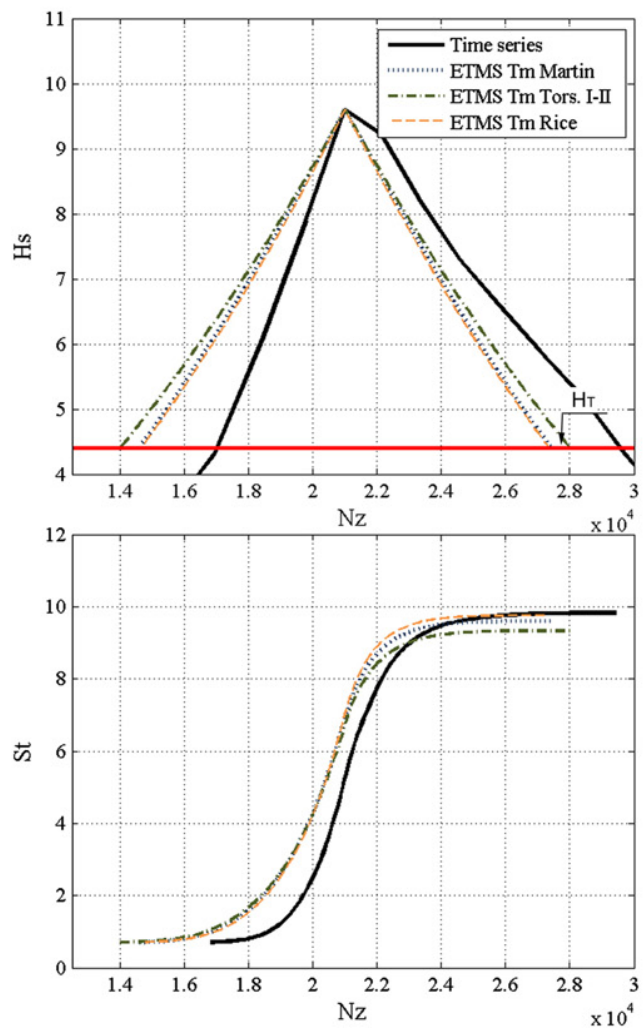

storms. However, the model underestimates damage for more developed sea states. Underassessment occurs because when establishing the base, the duration of the storm theoretical shape, as a function of the maximum expected wave height, $H_{\max }$, does not consider that
ETDS
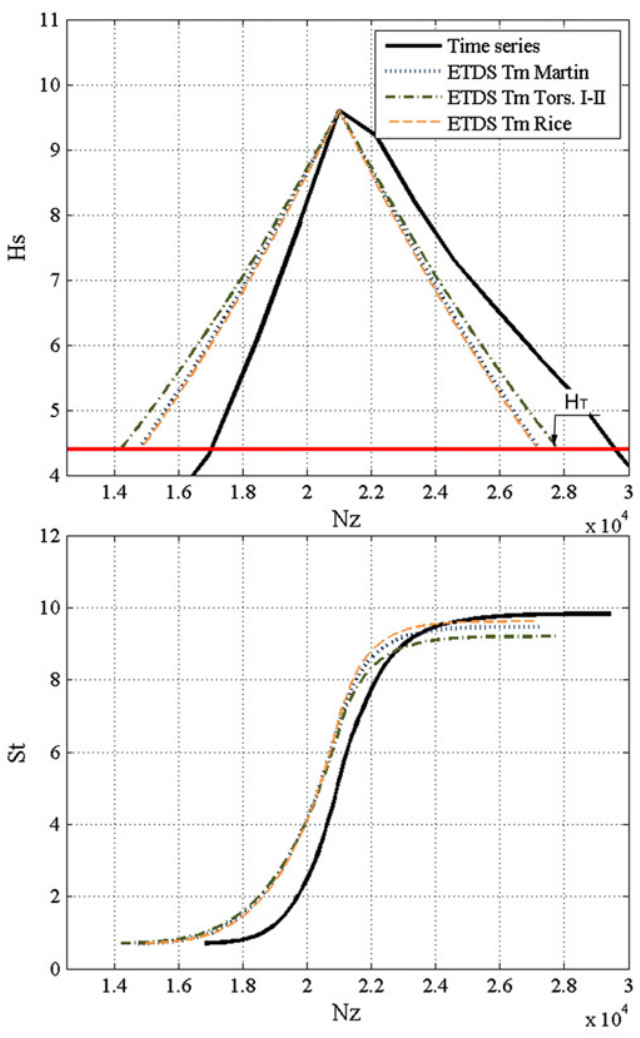

ETNWS
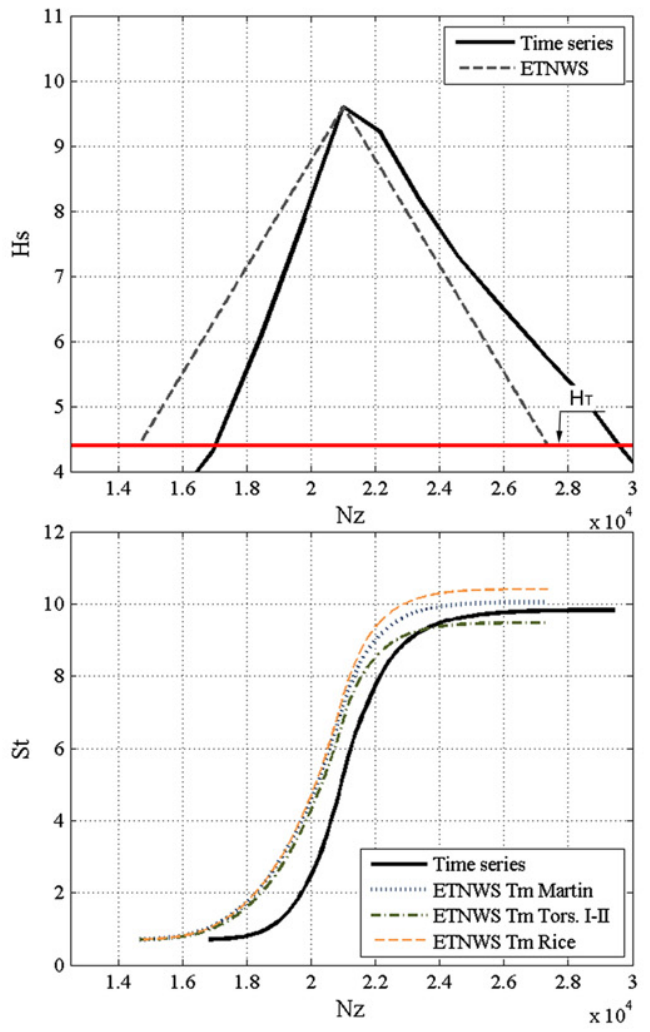

sea states with a lower $H_{\max }$ but a higher period result in a greater energy flow withstood by structure. Obviously, this effect is all the more notorious if the greater is the degree of the sea state's development. 
The EPS model proposed by Fedele et al. (2010), in its two versions, $\lambda=0.75$ and $\lambda=2$, overestimates the damage irrespective of the storm's degree of development.

The ETDS, ETMS and ETNWS models adequately reproduce damage progression. However, the most versatile one is the new ETMS giving the best results for both typical sea storms and more developed sea states.

The choice of adjustment model in the mean period associated to each sea state is also important. The versatile adjustment of Martín Soldevilla et al. (2009) is the only one applicable both to wind waves and swell waves and its use is therefore recommended.

Although the results obtained in this study show the triangle storm shape acceptable for reproducing the general storms' behaviour, investigations being carried out at the present moment, employing different geometric shapes, seem to point towards the need to use other geometrical shapes in order to characterise the history of storms associated to sea states with heavy swell component influence. When the results of this study have been in depth analysed using storms with different characteristics, the theoretical shapes most suited to each type of storm will be established including a simplified procedure for its characterisation and subsequent extrapolation to the return periods required in the standard national codes for each type of structure. The use of copulas is extraordinarily advantageous for extrapolating storms with data outside the region, which is necessary to characterise breakwater design storms, allowing direct control of each of the variables defining the extreme event analysed to be obtained.

In order to validate the relevant statistical characterisation, it is planned to apply the characterisation theory of the storm's history to analysing other ultimate (i.e. rear armour erosion, toe erosion...) and serviceability (overtopping...) limit states.

\section{Acknowledgement}

The CEDEX financed the grant and our thanks go to both the CEDEX for providing such support and to the Madrid Technical University for placing its resources and facilities at the disposal of the PhD. course.

\section{References}

Arena, F., Fedele, F., 2002. Intensity and duration of sea storms off the Californian coast. Proc of Solutions to Coastal Disasters '02. Soc. of Civ. Eng. San Diego, USA, pp. 126-141.

Barbaro, G., Foti, G., 2012. Shoreline behind a breakwater: comparison between theorical models and field measurement for the Reggio Calabria Sea. J. Coast. Res.

Biondi, F., Kozubowski, T.J., Panorska, A.K., 2002. Stochastic modeling of regime shifts. Clim. Res. 23, 23-30.

Boccotti, P., 1997. A general theory of three-dimensional wave groups. Ocean Eng. 24, 265-300

Boccotti, P., 2000. Wave Mechanics for Ocean Engineering. Elsevier Science, Oxford.

Borgman, L.E., 1970. Maximum wave height probabilities for a random number of random intensity storms. Proc. 12th Conf. Coastal Engineering, Washington, DC. ASCE, pp. 53-64.

Borgman, L.E., 1973. Probabilities for highest wave in hurricane. J. Waterw. Port Coast. Ocean Eng. 99, 185-207.

Cialone, M.A., Butler, H.L., Amein, M., 1993. DYNLET1 application to federal highway administration projects. Miscellaneous Paper CERC-93-6.U. S. Army Engineer Waterways Experiment Station.

Coles, S.G., Tawn, J.A., 1994. Statistical methods for multivariate extremes: an application to structural design. J. R. Stat. Soc.: Ser. C: Appl. Stat. 43, 1-48.

Coles, S., Heffernan, J., Tawn, J., 1999. Dependence measures for extreme value analyses. Extremes 2, 339-365.

Corbella, S., Stretch, D.D., 2012a. Multivariate return periods of sea storms for coastal erosion risk assessment. Nat. Hazards Earth Syst. Sci. 12, 2699-2708.

Corbella, S., Stretch, D.D., 2012b. Predicting coastal erosion trends using non-stationary statistics and process-based models. Coast. Eng. 70, 40-49.

Corbella, S., Stretch, D.D., 2013. Simulating a multivariate sea storm using Archimedean copulas. Coast. Eng. 76, 68-78.

De Michele, C., Salvadori, G., 2003. A generalized Pareto intensity-duration model of storm rainfall exploiting 2-copulas. J. Geophys. Res. Atmos. 108, 4067.

De Michele, C., Salvadori, G., Passoni, G., Vezzoli, R., 2007. A multivariate model of sea storms using copulas. Coast. Eng. 54, 734-751

Etemad-Shahidi, A., Bali, M., 2012. Stability of rubble-mound breakwater using H50 wave height parameter. Coast. Eng. 59, 38-45.
Fedele, F., Arena, F, 2009. The equivalent power storm model for long-term predictions of extreme wave events. Proc. of the 28th International Conference on Ocean, Offshore and Arctic Engineering (OMAE 2009). American Society of Mechanical Engineers (ASME).

Fedele, F. Arena, F., Tayfun, M.A., 2010. Extreme waves of sea storms. Proceedings of the ASME 29th International Conference on Ocean, Offshore and Arctic Engineering 2010 OMAE 2010, pp. 179-188 (2)

Goel, N.K., Seth, S.M., Chandra, S., 1998. Multivariate modeling of flood flows. J. Hydraul. Eng. 124, 146-155.

Guedes Soares, C., Scotto, M., 2001. Modelling uncertainty in long-term predictions of significant wave height. Ocean Eng. 28, 329-342.

Hawkes, P.J., Gouldby, B.R., Tawn, J.A., Owen, M.W., 2002. The joint probability of waves and water levels in coastal engineering design. J. Hydraul. Res. 40, 241-251.

HR Wallingford and Lancaster University, 2000. The joint probability of waves and water levels: JOIN-SEA: a rigorous but practical new approach. HR Wallingford Report SR 537.

Hughes, S.A., 2004. Wave momentum flux parameter: a descriptor for nearshore waves. Coast. Eng. 51, 1067-1084.

Lepetit, J.P., Feuillet, J., 1979. Study of the stability of a rubble mound breakwater under random waves. Quantification of the Effect of Duration. EDF-LNH Report 42 $79,15$.

Martín Soldevilla, M.J., Aberturas Ajenjo, P., 2001. Progresión de la probabilidad de fallo de diques en talud con tormentas de distintas características. VI Jornadas españolas de ingeniería de Costas y Puertos.

Martín Soldevilla, M.J., Aberturas, P., Serrano, O., 2009. Caracterización bivariada de los temporales en la costa española para su aplicación al diseño de estructuras (ROM 0.0). X Jornadas españolas de Costas y Puertos.

Medina, J.R., 1996. Wave climate simulation and breakwater stability. Coastal Engineering Proceedings, pp. 1789-1802.

Medina, J.R., 1997. Simuladores de clima marítimo en los análisis de estabilidad de diques en talud. IV Jornadas Españolas de Ingeniería de Costas y Puertos.

Melby, J.A., 1999. Damage progression on rubble-mound breakwaters. Ph. D. Dissertation University of Delaware, Newark, Delaware. Technical Report CHL-99-17. Coastal and Hydraulics Lab., US Army Engineer R\&D Center, Vicksburg, MS

Melby, J.A., Kobayashi, N., 1998. Progression and variability of damage on rubble mound breakwaters. J. Waterw. Port Coast. Ocean Eng. ASCE 124, 286-294.

Melby, J.A., Kobayashi, N., 2000a. Damage development on stone-armored rubble mounds. Coast. Eng 276, 1571-1584.

Melby, J.A., Kobayashi, N., 2000b. Damage progression and variability on breakwater trunks. International Conference, Coastal Structures '99, pp. 309-315.

Melby, J.A., Kobayashi, N., 2011. Stone armor damage initiation and progression based on the maximum wave momentum flux. J. Coast. Res. 27, 110-119.

Melby, J.A., Nadal, N.C., Males, R.M., 2011. Breakwater-harbor time-dependent life-cycle analysis software. Proc. of Coastal Structures 2011

Morton, I.D., Bowers, J., 1996. Extreme value analysis in a multivariate offshore environment. Appl. Ocean Res. 18, 303-317.

Nerzic, R., Prevosto, M., 2000. Modelling of wind and wave joint occurrence probability and persistence duration from satellite observation data. Tenth International Offshore and Polar Engineering Conference, pp. 154-158.

Rice, S.O., 1945. Mathematical analysis of random noise. Bell Syst. Tech. J. 24, 46-156.

ROM 1.0-09 Recommendations for the Project Design and Construction of Breakwaters, 2009. Part I: calculation and project factors. Climate Agents.Puertos del Estado.

Shiau, J.T., Shen, H.W., 2001. Recurrence analysis of hydrologic droughts of differing severity. J. Water Resour. Plan. Manag. ASCE 127, 30-40.

Sobey, R.J., Orloff, L.S., 1999. Intensity-duration-frequency summaries for wave climate. Coast. Eng. 36, 37-58.

Teisson, C., 1990. Statistical approach of duration of extreme storms: consequences on breakwater damages. Proc., 22nd Int. Conf. Coastal Engineering, pp. 1851-1860.

Thompson, D.M., Shuttler, R.M., 1975. Riprap design for wind wave attack. A Laboratory Study in Random Waves. HRS Wallingford, UK Report 61.

Torsethaugen, K., Faanes, T., Haver, S., 1984. Characteristics for Extreme Sea States on the Norwegian Continental Shelf. NHL Norwegian Hydrodynamics Laboratory, Trondheim (Report 2-84123).

Tsimplis, M.N., Blackman, D., 1997. Extreme sea-level distribution and return periods in the Aegean and Ionian Seas. Estuar. Coast. Shelf Sci. 44, 79-89.

Van der Meer, J., 1988. Rock slopes and gravel beaches under wave attack. Ph. D. Dissertation Delft Hydraulics Communication, No. 396. Delft Hydraulics Laboratory, Emmeloord, The Netherlands.

Van der Meer, J.W., Pilarczyk, K.W., 1984. Stability of rubble mound slope under random wave attack. Proc 19th Int. Conf. Coastal Engineering, pp. 2621-2634.

Vidal, C., Losada, M.A., Mansard, E.P.D., 1995. Suitable wave-height parameter for characterizing breakwater stability. J. Waterw. Port Coast. Ocean Eng. ASCE 121, 88-97.

Vidal, C., Medina, R., Lomónaco, P., 2006. Wave height parameter for damage description of rubble-mound breakwaters. Coast. Eng. 53, 711-722.

Yue, S., Ouarda, T.B.M.J., Bobee, B., Legendre, P., Bruneau, P., 1999. The Gumbel mixed model for flood frequency analysis. J. Hydrol. 226, 88-100.

Zachary, S., Feld, G., Ward, G., Wolfram, J., 1998. Multivariate extrapolation in the offshore environment. Appl. Ocean Res. 20, 273-295.

Zevenbergen, L.W., Lagasse, P.F., Edge, B.L., 2004. Tidal hidrology, hydraulics and scour at bridges. Federal Highway Administration, Hyd. Eng'g Circular 25, Washington (170 pp.). 